\title{
A NOVEl APPROACH TO OPTIMIZE WATER AND FERTILIZERS IN AGRICULTURE USING IO'T
}

\author{
D.Louisa Mary $^{1}$,Dr.M.Ramakrishnan ${ }^{2}$ \\ ${ }^{1}$ Assistant Professor Department of Computer Application, St.John's \\ College, Palayamkottai, Tirunelveli, Tamil Nadu. \\ ${ }^{2}$ Professor \& Head, Department of Computer Application, Madurai \\ Kamarajar University, Madurai, Tamil Nadu.
}

\begin{abstract}
This paper presents a new method for supplying nutrients to the farm. This novel method uses IoT and Wireless Sensor Network in Farming. Soil Moisture sensor and humidity sensor monitor the soil properties. These results are updated to the IoT Server. Based on the values for humidity of the soil, drip irrigation to the plant is on/off through solenoid valve. In addition this paper concentrates on quantitative analysis of requirement of nutrients for the plant to avoid overdose or insufficiency of them. This work trains the machine using precision agriculture for supplying required nutrient to the plant using solenoid on/off valve through drip irrigation. It also alerts the user by sending SMS (Short Messaging Service) through GSM to the user on fertigation date and pesticides spraying date. This will be very helpful for the farmers to remember the fertigation date in their various activities. The limitation of this work is that the fertilizers used will only be liquid in state. This technology can also be improved to a large level agricultural production.
\end{abstract}

\section{KEYWORDS}

Iot, Wireless Sensor Network, Sensor, Drip Irrigation, Fertigation, Liquid Fertilizers

\section{INTRODUCTION}

The population rate is increasing in an exponential way in India. The Rainfall is also not adequate every year. So India suffers water scarcity every year. In this present scenario it is a very challenging task to do agriculture manually like sowing, digging and irrigating and to meet out the needs of food for the increased population. Hence, adequate modifications are required in agricultural field to increase the productivity and to maintain the quality with minimum water.

Smart farming is a good alternate hi-tech system to meet the needs of food in a better way for growing population. Wireless Sensor Network (WSN) and Internet of Things(IoT), as one of the exciting new fields of research, has great promise in addressing the emerging needs of the food in agriculture area and give more productivity and good avenues. Using this technology the process for agriculture is automated. Various Sensors pertaining to Soil moisture, temperature and humidity provide the necessary parameters about the soil and submit the same to the IoT Server based on which decision is made for drip irrigation. Thus water usage minimization is achieved.

Supplementing Fertilizers is also found to be very essential to increase the yield up to 25 to 50 percent. [16] Proper supplying of fertilizer discourages weed growth also. The correct quantity of 
nitrogen, Phosphorous, potassium used for plant growth, fruit and flowers and strong stems and also fight against diseases [17].

So required soil nutrients(NPK) are supplied to the land automatically on time in this proposed work with less human intervention with the help of WSN and IOT.

\section{RELATED WORK}

Researches of Carrnige Mellon University worked on plant nursery using Wireless Sensor Technology [9]. Wireless Sensor Network based poly house monitoring system is explained in [10] which accurately finds out environment temperature, humidity, $\mathrm{CO} 2$ level and sufficiency of light also. This poly house control technology provides automatic adjustment of poly house. In [11] authors have proposed development of WSN based detection of above mentioned parameters for agriculture using Zig Bee protocol and GPS technology. In some projects such as [12] authors have designed and implemented an approach in the development of crops monitoring system in real time to increase production of rice plants. Later on use of IoT has been proposed in [13].

In [1] a system is proposed for soil monitoring and fertigation in which Nitrogen $(\mathrm{N})$, Phosphorous $(\mathrm{P})$, potassium $(\mathrm{K})$ values are determined by comparing the solution with color chart. In [2], NPK Kit is used to test soil and dispense the fertilizer required. Using IoT \& Wireless Moisture Sensor Network (WMSN) feedback control method in greenhouse crop irrigation was proposed in [3].

Patil and Kale in [4] developed Android application to collect real time data and alerts through short Messaging Service(SMS). A paper using fuzzy rules to cultivate vegetables in terrace proposed in [5]. Ahmed et al. [6] experimented and explain the need of the correct mixture of fertilizer(NPK) on the lower chrysanthemum. An IoT system for tomato growing stages using deep learning model is explained in [14]. In [15] S. K. Y. Donzia , H.-K. Kim and H. J. Hwang proposed a framework for precision agriculture using IoT Gateway. In [8] we presented a smart farming system which applies drip irrigation and alert the user on date to spread fertilizers and pesticides.

\section{Proposed System Design}

Our Proposed work is illustrated in fig.2. This system is developed with Arduino Uno open source Microcontroller board based on the Microchip ATmega328P microcontroller with a CPU Microchip AVR (8-bit),Memory SRAM, and Flash, EEPROM memory for storage purpose It uses the following components

\subsection{Components}

Soil Moisture Sensor is used to measure the volumetric water content of soil and humidity sensors measures the moisture content and send that information to the IoT Server.

RTC - (Real Time Clock ) ds1307 RTC is used to monitor time and maintain calendar . In this work the Real time clock is on when the seed is planted and the seed planting date is stored in EEPROM of Arduino which will be useful for calculating the supply of nutrients(fertilizers) and pesticides to the plant on time. 
GSM -SIM800A based GSM/GPRS with dual frequency $900 / 1800 \mathrm{MHz}$ is used in this work . GSM(Global System for Mobile Communication) is used to send alert messages to the user to supply fertilizers and pesticides on time.

Relay and Solenoid valve: The required nutrient is applied to the field along with drip irrigation through the solenoid valve automatic switching ON/OFF and Relay control

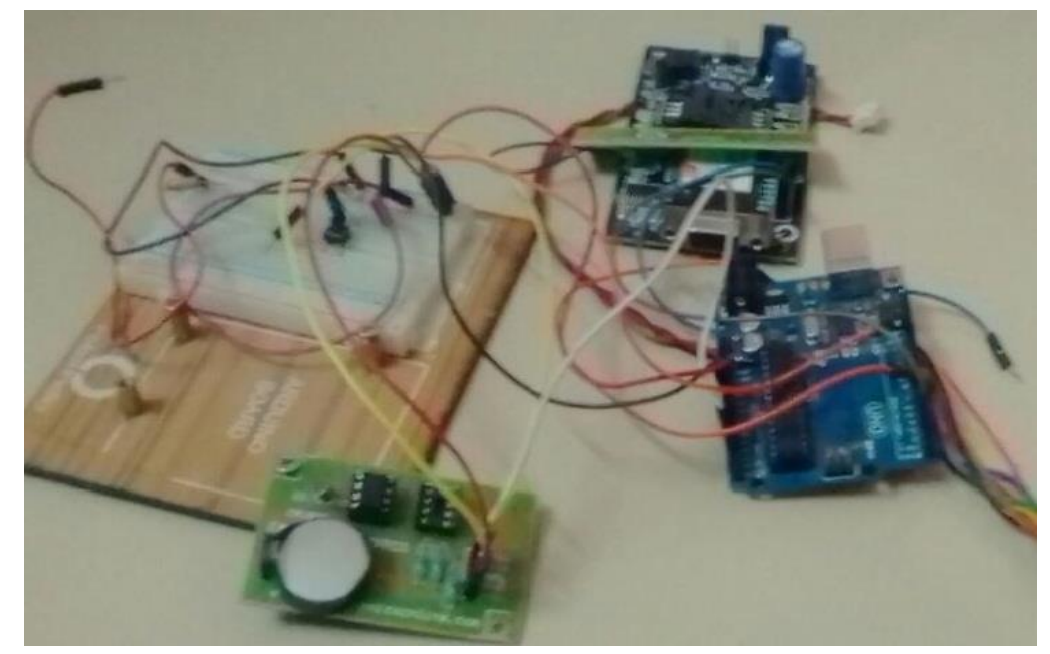

Fig-1 Arduino uno with RTC and GSM Relay connection

Arduino receives input from Soil Moisture sensor, humidity sensor, Real Time Clock(RTC) and produces the results to GSM, IoT Server.

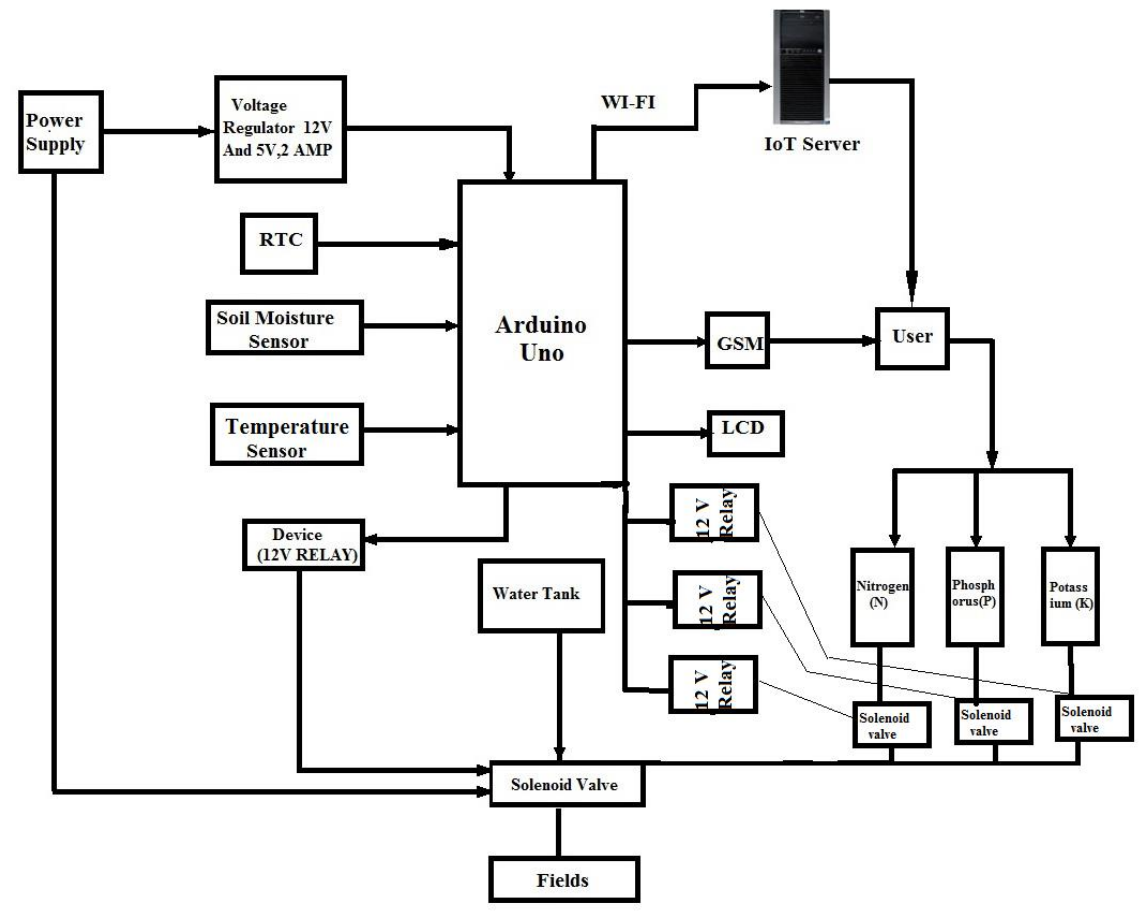

Fig-2 Overall Architecture 


\subsection{Proposed Method}

\subsubsection{Drip Irrigation}

Temperature sensor and Soil moisture sensor gets the values from the field and it is sent to the IoT server for analyzing. if the Soil moisture values are less than the expected threshold value, solenoid valve automatically opens and the plants are drip irrigated. Here the threshold value for soil moisture is considered as 50 percentage approximately.

\subsubsection{Notifying fertilizer date and Pesticides date}

Seed planting date is stored in memory if the current date is the fertilizer supplying date or pesticides spraying date then the machine were trained to alert the farmer by sending SMS(short messaging service) through GSM(Global System for Mobile Communications). The Circuit diagram for alerting the user is described below.

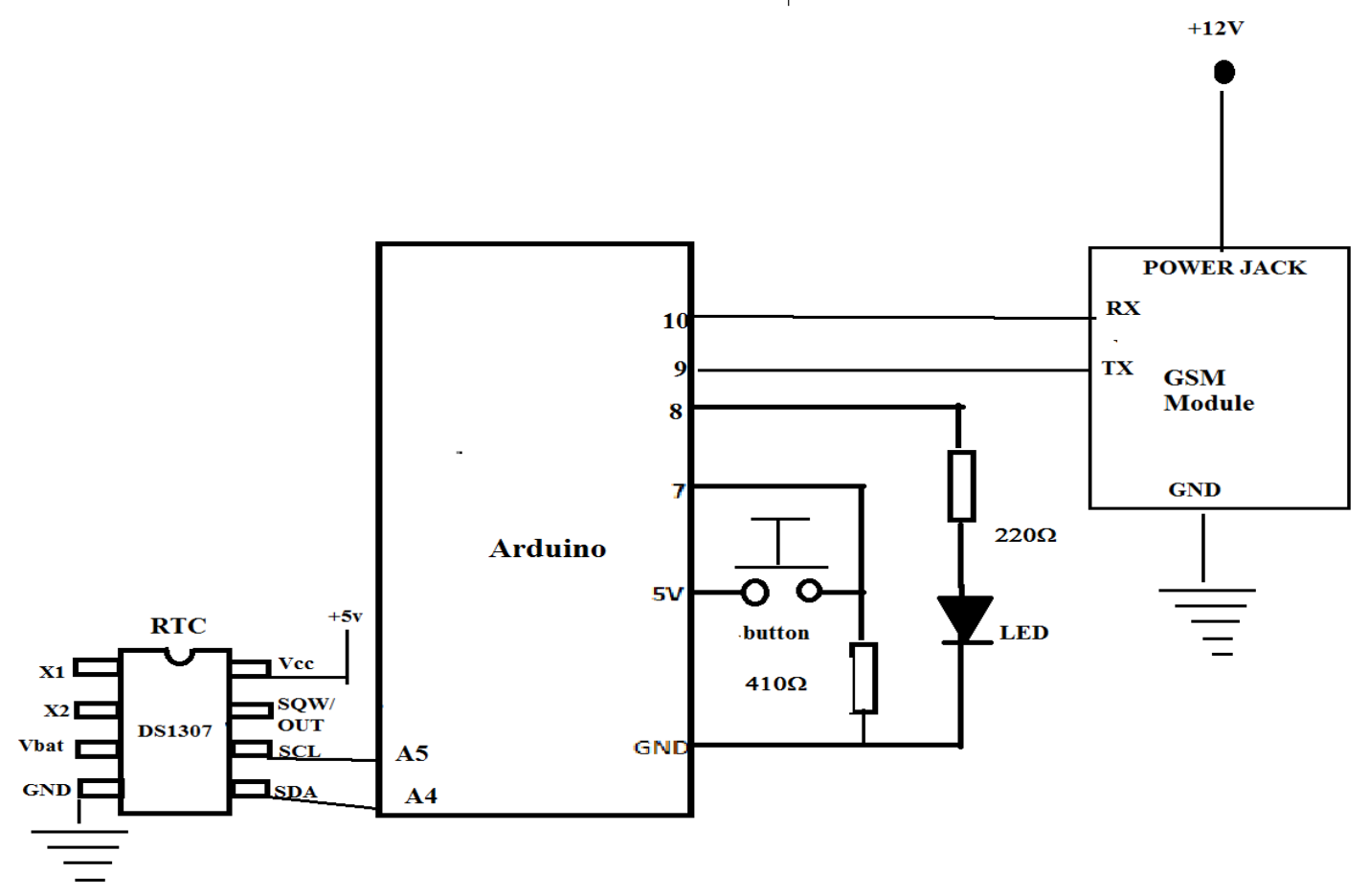

Fig.3: Circuit Diagram for alerting the user on fertilizer date[8]

\subsubsection{Algorithm for calculating the Nutrient to the Soil}

After getting the Nutrient details(NPK) about the soil from the lab the following steps are used for calculating the time needed to automatically apply the required nutrient to the soil through drip irrigation

Let the Quantity of Nutrient in Soil $=\mathrm{X} \mathrm{Kg} /$ hectare

1. Optimum Level=(threshold_value) $\mathrm{Kg} / \mathrm{ha}$

2. Needed $=($ threshold_value $-\mathrm{X}) / \mathrm{ha}$; 
3. Area of the actual land(A) = A1 hectare

4. The Nutrient needed for the actual land $($ Need_actual $)=$ Needed $*$ A ;

5. Flow Rate in one nozzle $=\mathrm{F} 1 / \mathrm{min}$;

6. Number of Nozzles for $\mathrm{A}=\mathrm{N} 1$;

7. Total Flow Rate $(\mathrm{TFR})=\mathrm{N} 1 * \mathrm{~F} 1$;

8. Nutrient $(\mathrm{N})$ Mixing Composition $=\mathrm{NF} \%$

9. Volume of Nutrient dispersed per minute $(\mathrm{V})=(\mathrm{NF} / 100) * \mathrm{TFR}$;

10. One litre of Fertilizer contain $(\mathrm{FN})=$ Nutrient in $\mathrm{Kg}$;

10.1. Weigh Fertilizers supplied per minute $(\mathrm{W})=\mathrm{V} * \mathrm{FN}$;

10.2. Time Needed to spray the required nutrient $(\mathrm{t})=((1 / \mathrm{W}) *$ Need_actual $) /$ minute

11. Repeat all the above steps for all nutrients which are applied to the farm through drip and find the time needed for them to spray.

12. After the time is calculated for all nutrients, compare all the time and find the maximum time used by the nutrient to spray in the farm.

13. Taking Maximum time as nutrient spraying time and adjust the solenoid valve using the below calculation for the remaining nutrient and apply them to the farm simultaneously using drip irrigation .

13.1. Let $\mathrm{N} 1, \mathrm{~N} 2, \mathrm{~N} 3$ be the time taken in minutes by the Nutrient1,Nutrient2,Nutrient3 and maximum time is Max .

13.2. Solenoid valve for Nutrient1, Nutrient2,Nutrient3 is adjusted as N1/Max,N2/Max,N3/Max minutes

14. Finally Solenoid valve automatically switched off when the time is over.

15. End

\section{RESUlTS AND DisCUSSIONS}

Soil Moisture Sensor and humidity sensor senses the moisture contents of the field and send the details to the Server. If the Moisture content values are less than the threshold value, solenoid valve automatically opens and start drip irrigation. Through RTC seed sowing date is stored in EEPROM and from that detail nutrient spraying date and pesticides date are calculated. It sends an SMS to the user on that calculated date through GSM.

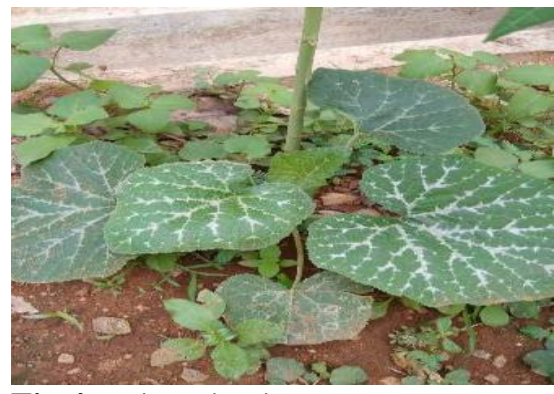

Fig.4. Drip Irrigation [7]

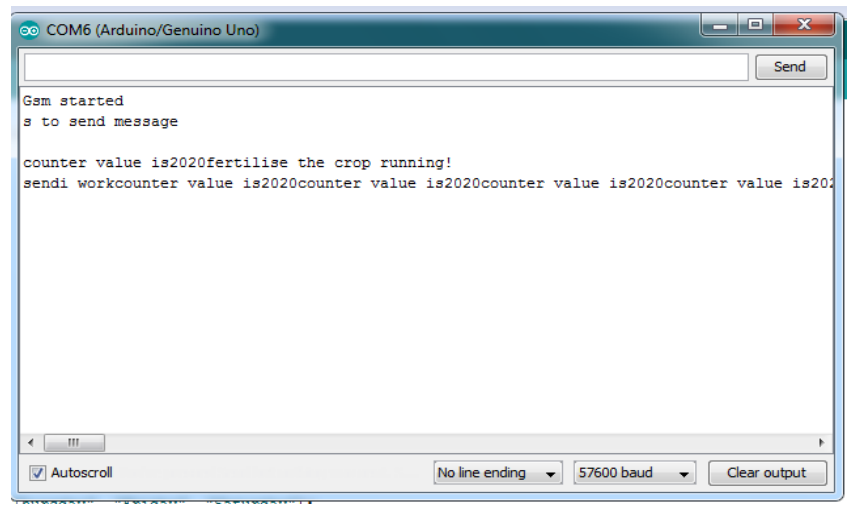

Fig.5. Serial Monitor output for alerting the user[8]

Fig.4 shows that the plants are drip irrigated and Fig.5 shows serial monitor output of arduino which shows that GSM is sending SMS alerts to the user for applying fertilizers. In between time the farmers collect the soil and test the nutrient percentage in the Lab. When he/she gets the SMS , He/She supply the required nutrient to the soil through drip irrigation. 
The Threshold value for $\mathrm{N}, \mathrm{P}, \mathrm{K}$ is fixed which is taken from Tamil Nadu AgriculturalPortal.

Table 1: Nutrient Value [16]

\begin{tabular}{llll}
\hline Nutrient & Low & Medium & High \\
\hline Available Nitrogen(N) & $<240 \mathrm{Kg} / \mathrm{ha}$ & $240-480 \mathrm{Kg} / \mathrm{ha}$ & $>480 \mathrm{Kg} / \mathrm{ha}$ \\
& & & \\
Available Phosphorus(P) & $<11.0 \mathrm{Kg} / \mathrm{ha}$ & $11-22 \mathrm{Kg} / \mathrm{ha}$ & $>22 \mathrm{Kg} / \mathrm{ha}$ \\
Available Potassium(K) & $<110 \mathrm{Kg} / \mathrm{ha}$ & $110-280 \mathrm{Kg} / \mathrm{ha}$ & $>280 \mathrm{Kg} / \mathrm{ha}$ \\
& & & \\
\hline
\end{tabular}

Taking threshold value for the Nitrogen(N), Phosphorus(P) and Potassium(K) as 480,Kg,22g, 280 $\mathrm{Kg}$ respectively from the above table which was taken from tamil nadu agricultural portal and apply this value in the algorithm given in section 3 and supplied to the farm through drip.

Arduino automatically calculates the needed nutrients and how much time is needed to spray the needed nutrients .

Table 2: The results obtained from the proposed algorithm

\begin{tabular}{llllll}
\hline Nutrient Name & $\begin{array}{l}\text { Nutrient fertilizer } \\
\text { Mixing } \\
\text { composition(\%) }\end{array}$ & $\begin{array}{l}\text { Volume of } \\
\text { Nutrient } \\
\text { dispersed } \\
\text { /minute }\end{array}$ & $\begin{array}{l}\text { one litre of } \\
\text { fertilizer } \\
\text { contained } \\
\text { nutrients in } \\
\text { kg }\end{array}$ & $\begin{array}{l}\text { Weigh } \\
\text { Fertilizer } \\
\text { supplied in } \\
\text { kg }\end{array}$ & $\begin{array}{l}\text { Time } \\
\text { needed } \\
\text { to spray } \\
\text { in min }\end{array}$ \\
\hline Nitrogen(N) & 5 & 30 litres & 0.5 & 15 & 6 \\
Phosphorus(P) & 3 & 18 litres & 0.5 & 1.8 & 2 \\
Potassium(K) & 5 & 30 litres & 0.5 & 15 & 3 \\
\hline
\end{tabular}

Here Nutrient fertilizer mixing composition (\%) and fertilizer contained nutrient in one litre values are arbitrarily taken..

Here the maximum time is 6 minutes for Nitrogen fertilizer.

Solenoid valve for nitrogen will open 6 minutes and solenoid valve for Phosphorous and Potassium is adjusted to $(2 / 6)=3$ minutes and $(3 / 6)=2$ minutes . (based on the step 10 in the above procedure)

Hence the total time needed for the above fertilizers(NPK) to spray is 6 minutes .

\section{SCOPE OF THE WORK}

In future more parameters can be monitored and controlled. Soil Moisture threshold value will be calculated using fuzzy logic method. Instead of testing NPK of soil in the lab, sensors can be used to detect NPK value and automatically takes the required nutrient quantity from the tank. This system can also use android application. Detection of insecticides can also be added in our future work. 


\section{CONClusion}

This system applies the drip irrigation to the plant automatically. And also it informs the user to spray the fertilizers, pesticides on time. It calculates the required quantity of nutrient to the soil and supply it through the drip irrigation which saves more water and produce more yield. All the data will be sent to the server for monitoring and analyzing purpose.

\section{REFERENCES}

[1] SR. Raut, H. Varma, C. Mulla and Vijaya Rahul Pawar Soil Monitoring, Fertigation, and Irrigation System Using IoT for Agricultural Application Springer Nature Singapore Pte. Ltd. 2018 Y.-C. Hu et al. (eds.), Intelligent Communication and Computational Technologies, Lecture Notes in Networks and Systems 19.

[2] Dr. A. D. Shaligram, Nishant Singh, "NPK Measurement in Soil \& Automatic Soil Fertilizer Dispensing Robot", International Journal of Engineering Research \& Technology (IJERT) Vol.3, Issue 7, July. 2014.

[3] Ibrahim Mat, Mohamed Rawidean Mohd Kassim, Ahmad Nizar Harun, Ismail Mat Yusoff MIMOS, IoT in Precision Agriculture Applications Using Wireless Moisture Sensor Network, Ministry of Science ,Technology and Innovation, Kuala Lumpur, MALAYSIA 2016 IEEE Conference on Open Systems (ICOS), October 10-12, 2016, Langkawi, Malaysia

[4] Prof. K. A. Patil, Prof. N. R. Kale A Model for Smart Agriculture Using IoT, 2016 International Conference on Global Trends in Signal Processing, Information Computing and Communication

[5] V. Pandiyaraju*, P. Shunmuga Perumal, A. Kannan and L. Sai Ramesh ," SMART TERRACE GARDENING WITH INTELLIGENT ROOF CONTROL ALGORITHM FOR WATER CONSERVATION Pak. J. Agri. Sci., Vol. 54(2), 451-455; 2017 ISSN (Print) 0552-9034, ISSN (Online) 2076-0906

[6] R. Ahmed, M.J. Hussain, S. Ahmed, M.R. Karim1 and M.A. Siddiky,” Effect of N, P and K fertilizer on the flower yield of Chrysanthemum" A Scientific Journal of Krishi Foundation, The Agriculturists 15(1): 58-67 (2017) ISSN 2304-7321 (Online), ISSN 1729-5211 (Print)

[7] D.Louisa Mary, Dr.M.Ramakrishnan 2019, IOT BASED MONITORING SYSTEM IN HOME AGRICULTURE Journal of Emerging Technologies and Innovative Research 2019 JETIR June 2019, Volume 6, Issue 6 DOI : http://doi.one/10.1729/Journal.22262.

[8] Louisa Mary, Dr.M.Ramakrishnan, Abraham N R Singh 2020, Performance of Smart Farming through Drip Irrigation and Managing of Fertilizers and Pesticides through IoT and GSM International Journal of Engineering and Advanced Technology (IJEAT) ISSN: 2249 - 8958, Volume-9 Issue-3, February, 2020

[9] Junaid ahmed zubairi , "Application of modern high performance networks" Bentham science publishers Ltd. 2009, pg. 120-129.

[10] Yongxian Song, Juanli Ma, Xianjin Zhang, Yuan Feng, "Design of Wireless Sensor Network-Based Greenhouse Environment monitoring and Automatic Control System", JOURNAL OF NETWORKS, VOL. 7, NO. 5, MAY 2012.

[11] G.V.Satyanarayana, SD.Mazaruddin, "Wireless Sensor Based Remote Monitoring System for Agriculture using ZigBee and GPS", Conference on Advances in Communication and Control Systems 2013.

[12] N.Sakthipriya, “An Effective Method for Crop Monitoring Using Wireless Sensor Network”, Middle East Journal of Scientific Research 20(9):1127-1132, 2014 ISSN 1990-9233.

[13] Alexandros Kaloxylos "Farm management systems and the Future Internet era", Computer and Electronics in Agriculture 89(2012)130144.

[14] Nuttakarn Kitpo ; Yosuke Kugai ; Masahiro Inoue ; Taketoshi Yokemura ; Shinichi Satomura,'Internet of Things for Greenhouse Monitoring System Using Deep Learning and Bot Notification Services”, 2019 IEEE International Conference on Consumer Electronics (ICCE) 
[15] Symphorien Karl Yoki Donzia, Haeng-Kon Kim and Ha Jin Hwang ," A Software Model for Precision Agriculture Framework Based on Smart Farming System and Application of IoT Gateway", Springer International Publishing AG, part of Springer Nature 2019 R. Lee (ed.),Computational Science/Intelligence \& Applied Informatics, Studies in Computational Intelligence 787, https://doi.org/10.1007/978-3-319-96806-3_4

[16] http://agritech.tnau.ac.in/agriculture/agri_soil_soilratingchart.html

[17] https://web.extension.illinois.edu/firstgarden/basics/feedme_03.cfm

[18] Jan Holler, VlasiosTsiatsis, Catherine Mulligan, Stefan Avesand, Stamatis Karnouskos, David Boyle, "From Machine-to-Machine to the Internet of Things: Introduction to a New Age of Intelligence", 1st Edition, Academic Press, 2014. (ISBN-13: 978-0124076846)

\section{Authors}

D.Louisa Mary Assistant Professor of Computer Science, St John's College, Palayamkottai has been teaching computer science for the past 13 years. To her credit she has M.Tech degree along with M.CA., M.Phil. She has also qualified SET. Her area of interest is Applications of computers in agriculture.

Dr.M.Ramakrishnan is the Head of the Department of Computer Applications Madurai Kamaraj University, Madurai. He has so far produced fifteen PhD's and he has published many papers in reputed journals. He published two books in Computer Science. His area of research is Network Security.
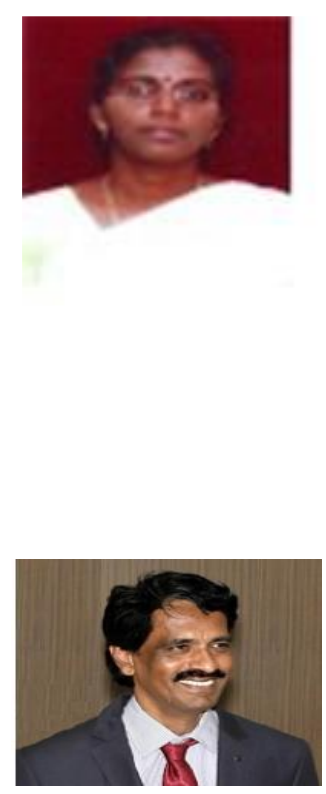